\title{
CHROMOBLASTOMYCOSIS: A RARE CASE OF INFECTION BY Fonsecaea compacta FROM WESTERN MAHARASHTRA, INDIA
}

\author{
ANGADI K.M., MISRA R.N., GANDHAM N.R., MOUMITA S., VYAWAHARE C.R., SINGHANIA S.S. AND \\ JADHAV S.V.*
}

Department of Microbiology, Padmashree Dr. D.Y. Patil Medical College, Hospital and Research Centre, Dr. D.Y. Patil Vidyapeeth, Pimpri, Pune- 411018, MS, India.

*Corresponding Author: Email- patilsv78@gmail.com

Received: December 01, 2012; Accepted: December 10, 2012

\begin{abstract}
Chromoblastomycosis is a fungal infection of the cutaneous and subcutaneous tissues. It is non contagious and chronic fungal infection. Several species of pheoid or dematacious fungi which are saprophytes are the causative agents. Infection occurs when the causative agent enters the body with trauma especially with wood splinters or thorn pricks. Diagnosis is done by demonstration of sclerotic bodies or Medlar bodies in $\mathrm{KOH}$ mounts and histopathological examination, culture on Sabourauds agar and by Molecular and Serological methods.

Case Presentation: A 50 year old male patient presented with. multiple plaques over the scalp and on the nape of the neck over the last 1 month, It was associated with itching. He did not give any history of injury but carried wood on his head and shoulders. The condition was diagnosed as Tinea capitis and skin scrapings sent for microscopic examination and fungal culture. Laboratory diagnosis. The diagnosis of Chromoblastomycosis by Fonsecaea. compacta (F. compacta) was made based on the finding of sclerotic bodies in $\mathrm{KOH}$ mounts and characteristic growth on SDA. Conclusions:- Chromoblastomycosis presenting as a plaque like lesions should be considered as it may be confused with other superficial dermatic lesions.
\end{abstract}

Keywords- Chromoblastomycosis, Fonsecaea compacta, Sclerotic bodies

Citation: Angadi K.M., et al (2012) Chromoblastomycosis: A Rare Case of Infection by Fonsecaea compacta from Western Maharashtra, India. International Journal of Microbiology Research, ISSN: 0975-5276 \& E-ISSN: 0975-9174, Volume 4, Issue 9, pp.-330-331.

Copyright: Copyright@2012 Angadi K.M., et al. This is an open-access article distributed under the terms of the Creative Commons Attribution License, which permits unrestricted use, distribution and reproduction in any medium, provided the original author and source are credited.

\section{Introduction}

Chromoblastomycosis is a chronic fungal infection of the cutaneous and subcutaneous tissue of the exposed portion of the body caused by demataceous fungi. Max Rudolph, a German Physician from Brazil was the first to describe hromoblastomycosis in 1914. The histopathological features of the disease and the pathognomic sclerotic cells were described 1 year later in 1915 by both Lane and Medlar [1,2]. The five principal etiological agents of chromoblastomycois are Fonsecaea pedrosoi (F. pedrosoi), Phialophora verrucosa ( $P$. verrucosa), Fonsecaeca compacta, Cladophialophora carrionii (C. carrionii) and Rhinocladiella aquaspersa. Virtually all cases of Chromoblastomycosis are caused by F. pedrosoi, C. carrionii and $P$. verrucosa. Infection with $F$. compacta is rarely reported as the etiologic agent of chromoblastomycosis in humans [3]. Chromoblastomycoss is known to occur in farmers. Injury by wood splinters or thorn prick is responsible for the entry of the organisms inside the body. The disease is common in men than women and is common after 30-50 years. Infection in children and adolescents have also been reported $[4,5]$. It usually occurs on the lower ex- tremities but can occur on any exposed portion of the body. Rare sites reported are nasal ala, ear, penile shaft, vulva, tracheolaryngeal region, tonsil, ileocaecal region and pleural cavity [6].

\section{Case Report}

A 58 year old patient hailing from Satara District was admitted to the hospital for cataract surgery. He complained of lesions on this head and neck over 1 month and also complained of itching in these areas. He did not give any history of injury but carried wood on his shoulders and head. Blood counts, Peripheral blood smear, Liver and kidney function test, chest X-ray were all normal. On examination plaques were seen all over the scalp and neck [Fig-1] and was diagnosed as Tinea capitis. He was given Greiseofulvin and skin scrapings were sent for microbiological diagnosis.

\section{Laboratory diagnosis}

Skin scrapings were examined by $10 \% \mathrm{KOH}$ and by culture on Sabourauds Dextrose agar. KOH mount revealed copper coloured, globe shaped, thick walled structures 4-12um in diameter with septa which were arranged in clusters [Fig-2]. Culture on Sabourauds 
revealed black coloured, heaped and folded colonies. The reverse of the slant showed jet black colour. Lactophenol cotton blue mounts showed hyphae which were septate, brown, branched and had predominantly cladosporium type conidiophores with branching chains and masses of almost round conidia [Fig-3]. The conidia were cask shaped with the wide diameter of the septa between conidia and the conidial chains were compactly arranged.

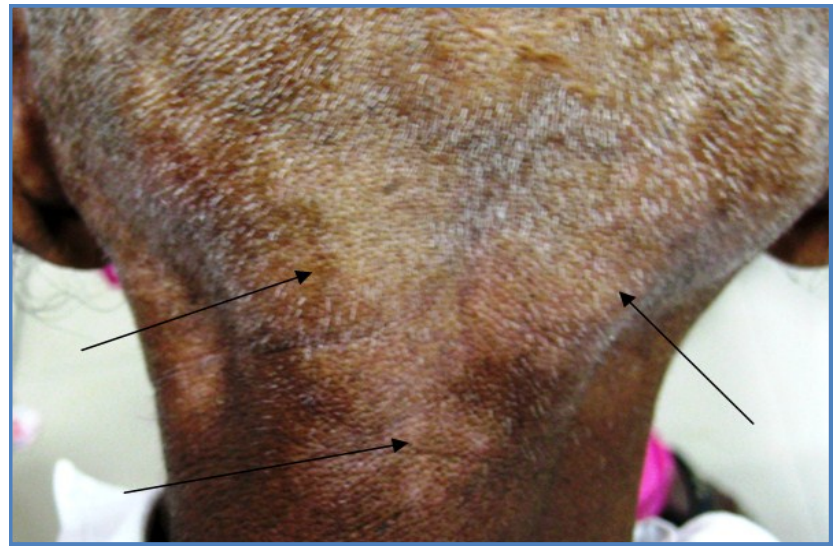

Fig. 1- Plaques on scalp and neck

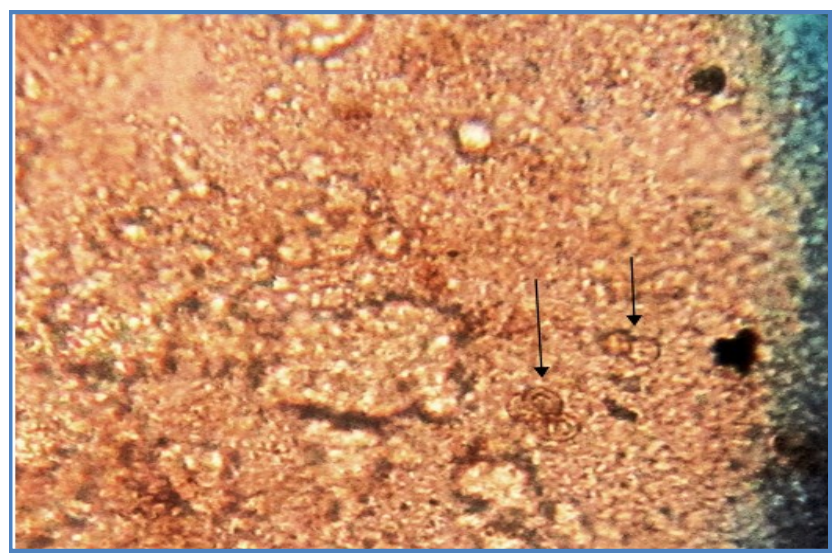

Fig. 2- $\mathrm{KOH}$ mount showing Sclerotic bodies

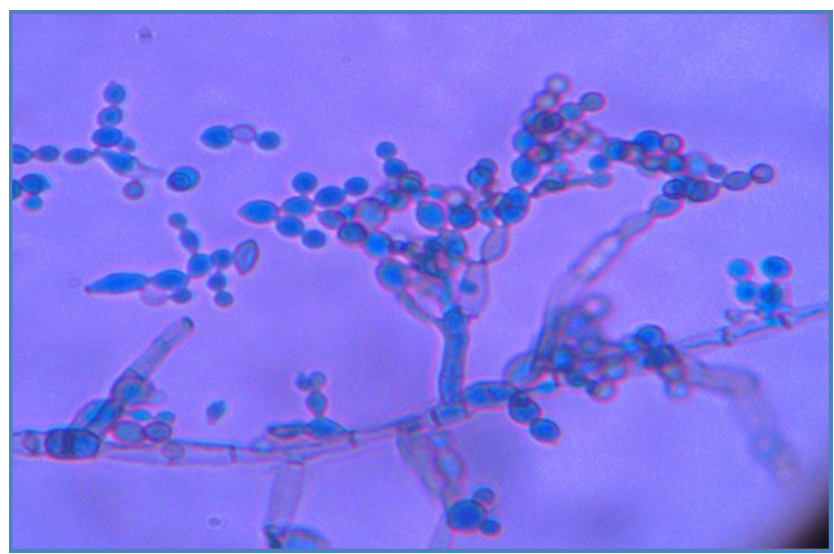

Fig. 3- Septate branched conidiophores with masses of conidia

\section{Discussion}

Chromoblastomycosis is distributed worldwide although it is more common in subtropical and tropical countries. Large numbers of cases have been reported from Madgascar in Africa, Brazil and
Japan. Several studies have shown that it is prevalent in several other countries as well like Thailand, Korea, Pakistan $[4,7,8]$. The five types of lesions described by Carrion in chromoblastomycosis are nodules, tumours, plaques, warty lesions [9]. It is a chronic disease and one of the most difficult mycotic infections to eradicate. It can be confused with various diseases like Cutaneous Tuberculosis, Cutaneous Leishmaniassis, Sporotrichosis, Squamous cell carcinoma etc. A high degree of clinical suspicion and diagnosis by mycological investigations play a pivotal role. Itraconazole and terbenfine are uuseful for the treatment of this disease. Other modalities of treatment are surgical excision, cryosurgeries with liquid nitrogen for localised lesions. Infection by $F$. compacta. is rare worldwide with only 12 cases reported till 1997 [10]. Attapattu, et al in a study from Sri Lanka has reported isolation of 2 cases of $F$. compacta [10]. In India, isolation of $F$. compacta has been reported in only one study by Sharma, et al. from Shimla wherein the isolation rate of $F$. compacta was $15 \%$ [6].

\section{Conclusion}

Our case is probably the only case of Chromoblastomycosis caused by $F$. compacta to be reported from Maharashtra. A high index of clinical suspicion and mycological investigation help in the diagnosis of such condition.

\section{References}

[1] Lane C.G. (1915) J. Cutan. Dis., 33, 840-6.

[2] Medlar E.M. (1915) J. Med. Res., 32, 507-22.

[3] Philippe Esterre (2005) Medical Mycology, 10th ed., 347-55.

[4] Inamullah Khan, Abdur Rahim Khan, Mohammad Sheraz Khan (2012) Journal of Pakistan Association of Dermatologists 22, 122-125.

[5] Blanco M.P., Valles R.H., Humbria G., Yegres F. (2006) Medical Mycology, 1-5.

[6] Sharma N.L., Sharma R.C., Grover P.S., Gupta M.L., Sharma A.K., Mahajan V.K. (1999) Int. J. Dermatology, 38(11), 846-51.

[7] Dong Min Kim, Sung Min Hwang, Moo Kyu Suh, Gyoung Yim $\mathrm{Ha}$, Gwang Seong Choi, Jeonghyun Shin, Sung Hyub Han (2011) Ann. Dematol., 23(3).

[8] Vanittanakom N., Kwangsukstith C., Vanittanakom P. Khanjanasthiti (1989) J. Infect. Dis. Antimicrob. Agents, 6(4), 209-212.

[9] Carrion A.(1950) Ann. NY. Acad. Sci., 50, 1255-1282.

[10]Attapattu M.C. (1997) Mycopathologica, 137(3), 145-51. 